\title{
STRATEGIES IN SEARCHING HOMOGENEITY IN A FACULTY OF A POSTGRADUATE PROGRAM
}

\author{
Estratégias na busca da homogeneidade do corpo docente de um programa de pós-graduação
}

José G Cecatti, Karayna G Fernandes, Renato T Souza, Carla Silveira, Fernanda G Surita

A BSTRACT

\begin{abstract}
The professor plays a fundamental role in a graduate program, considering he/she is who plans and performs a great part of the tasks, and he/she is also responsible for spreading knowledge among students. The professor should use didactical resources for his/ her continuous qualification, being responsible for situations favoring the development of students who should learn according to the best and easier way. The homogeneity in the postgraduate program consists of having subgroups of research corresponding to the Areas of Concentration, where each subgroup works with some distinct topics of research. It is desirable that the staff of postgraduate program has a significant and high quality scientific production, homogeneously distributed among them. The professors must systematically search for resources for research in agencies supporting research, not only for sponsoring the studies, but also for adding value to the researchers involved in the whole activities. The postgraduate programs need to support the professional qualification of their staff who should improve their knowledge on epidemiology for clinical studies, ethics in research and teaching skills. Two characteristics of the postgraduate system in Brazil are the nucleation and solidarity, based on the capacity and/or interest of those more structured programs to help those beginners, cooperating with their activities. The Capes (the national governmental agency responsible for coordinating and evaluating all postgraduate programs in Brazil) valorizes the social insertion in the context of postgraduate programs' activities. It includes the recognition of activities with technological, cultural, educational and social impact as criteria for evaluation of the programs. Does exist an ideal model of postgraduate program? We think that there is no a mathematical formulae nor an ideal model for a postgraduate program. Each institution should make adaptations and search for improvements of their faculty and students' teams.
\end{abstract}

Key Words - Graduate Education; Academic Institutions; Medical Faculty; Knowledge Management.

\section{INTRODUCTION}

Importance of the teacher in postgraduate program

The teacher has a fundamental importance in the postgraduate program as is who plans and executes most of the tasks, and is also responsible for disseminating knowledge and method to students, encouraging them to carry out research activities since undergraduation, through scientific initiation programs. The teacher's responsibilities are not limited to the classes, seminars, conferences preparation and participation in conferences. It is of utmost importance the impact of their work on their student's activities, respecting the individuality of each professional' ${ }^{1}$. Thus, it is important to keep different ages, genders and thoughts on teaching staff in the same program. So, the ideas complement each other, keeping a renewed and versatile team, which strengthens the program.

The teacher should use continuous learning resources to get better qualification, and should create favorable conditions for the student to develop and learn in the best way with most facilities ${ }^{1}$. The teacher/student relationship is important to the development of postgraduate program, but is on the faculty profile the central structure (the pillar) of scientific academic activities of the program. A recent study evaluated the impact of Chinese publications in comparison with the formation of its postgraduate programs and showed that, despite being one of the countries that publishes the world greater number of articles, the quality/impact of these publications are far below of the desired. A reflection on this Chinese context is about the importance of qualifying the postgraduate program, prioritizing the faculty, not the amount of publications ${ }^{2}$. Although there are no concrete data on the situation in Brazil, probably the situation is very similar to that described for China.

In this paper key aspects of the faculty profile in terms of efficiency, productivity and quality of the teachers, doctors and post-docs training will be discussed, looking for the excellence level in the Capes evaluation.

\section{FACULTY OF A POSTGRADUATE PROGRAM}

Faculty homogeneity and heterogeneity

The homogeneity in the postgraduate group consists of the presence of research subgroups corresponding to fields where each subgroup works with some distinct topics of research. In general, there is a leader in each of these subgroups, who represents them and who serves as the main reference for both national and international connections that the group may have.

Homogeneity expects to achieve results in quantity and quality compatible with the desired level by the program, ie there should not be major differences in scientific production, the number of students, the quality of teaching and the ability to obtain grants from funding agencies as resources for the respective activities of research.

The postgraduate programs must have a significant number of teachers (average number in the area of Medicine III is 15 full teachers by program) that allows accomplishing their activities and can also include the constant faculty renewal process. It must be remembered, however, that the greater the number of teachers, the harder it is the desired homogeneity. It is important that in this group there are more experienced teachers (senior lecturers), less experienced teachers (junior professors) and intermediate teachers, so there is always professionals with great scientific and publishing potential, while others gain experience over the years. This system enables the constant training of teachers with potential to become good researchers, structuring balanced renovation and allowing the program to rely on teachers with high yield and other starting or ending their scientific activities.

To achieve such homogeneity in the teachers group is often challenging. Sometimes teachers of some institutions have widely divergent research fields and/or the faculty are very young or they are already finalizing their professional activities for retirement. An alternative to this heterogeneity is to integrate new collaborator researchers to this group, who can be identified by the participation in research networks.

The faculty of the institution should be diversified according to gender, age and thought, and contain at least $80 \%$ of full professors who contribute more effectively to the demands of the postgraduate program. Another relevant aspect for program qualification is encouraging teachers to carry out post-doctorate, preferably abroad with scholarship, in order to open new horizons and partnerships in research, in addition to qualifying the involved professionals. The main focus should be in the post-doctoral training for young teachers.

Before enrolled in a postgraduate program, new teachers

From the Programa de Pós-Graduação em Tocoginecologia, Departamento de Tocoginecologia, Faculdade de Ciências Médicas, Universidade Estadual de Campinas (Postgraduate Program in Obstetrics and Gynecology, Department of Obstetrics and Gynecology, School of Medical Sciences, University of Campinas), Campinas, SP, Brazil 
must have previous experience with research tutorial in undergraduate scientific initiation programs - whose tutorial expertise can be lower -, to have further guidance with master students and, only much later, be able to tutor doctoral students. It is an ongoing and dynamic process of in-service training, requiring the existence of clear rules to be followed, with the ultimate goal of a common better quality of all the postgraduate process. Another possibility, less explored, refers to the process of senior/junior teaching faculty mentoring that, when properly understood and implemented, facilitates the appropriateness of the young teaching to get all standards required by the program, particularly when the program already is high scored in the periodic evaluation.

It is essential that the faculty has a significant scientific production, quality and evenly distributed among teachers. The scientific production of the group must comply with the concept intended by the program. Much of this production occurs within a research group, but individual teacher's production should also be encouraged. To achieve the desired maximum score in the Capes evaluation, for example, scientific production must comply with the minimum requirements for each score category. These criteria need to be complied for at least $80 \%$ of full professors. This enables compensate some "seasonal" publication reduction problems of any faculty member when the group as a whole is strong.

Coordinators should also encourage teachers to participate in the editorial board of international journals, as well as in the review process of articles in periodicals, as this step is very important for the scientific improvement of teachers whose experience may improve the quality of publications produced by the group. Teachers should systematically seek resources for research from funding agencies, both to cover costs of the studies and to the enhancement of the researchers involved (teachers and students). Teachers should also be encouraged to apply for the CNPq Research Productivity Grant and to develop a good strategy of obtaining resources from funding sponsors (CNPq, FAPESP, CAPES, Bill and Melinda Gates Foundation, the World Health Organization, other institutions and foundations, etc.), so that the various research projects are covered by some type of financing. Each financing obtained is a victory, because there is great competition in the race for resources for research; so, funding will motivate all staff to produce more and better. Besides allowing more professionalism in research, typically financed projects also have the opportunity to share of equipment and infrastructure, which brings benefit for the research group and the institution as a whole, improving the conditions for carrying out other studies.

It is desirable that at least the leader or some group members have good relationship with government agencies such as Department of Health, Ministry of Health, the World Health Organization, and with some professional societies. This means a lot of advantages: knowledge on key priority issues to be addressed in institutional programs and information on the availability of financial resources for research, knowledge of technical groups and the possibility of working together, contact with professionals from other institutions facilitating the building of research networks, among others.

Research groups should structure their research projects following specific protocols for its design, ensuring best quality. Before starting a research, involved professionals, teachers and students, should have specific theoretical knowledge of each type of study design, following the guidelines/standardized checklists internationally accepted that will help to structure and enhance the study method (eg: CONSORT, PRISMA, STARD, STROBE and RATS).

CONSORT (Consolidated Standards of Reporting Trials), for example, is a protocol used for randomized controlled trials (RCT) that was developed by a group of editors and scientists to improve the quality of matching articles. That was because, before, there were many systematic errors that threatened the ethical and quality, reflecting poor scientific behavior ${ }^{3}$. Currently, most medical journals and national and international publishing groups require the follow-up to the CONSORT guidelines, as this facilitates evaluation and interpretation of randomized controlled trials, which also facilitates communication between the authors and editors ${ }^{4}$. This protocol can be accessed through the link: http://www.consort-statement.org/downloads.

STROBE (Strengthening the Reporting of Observational Studies in Epidemiology) is the guideline formulated by researchers, statisticians, epidemiologists and editors that aims to systematize the development and publication of observational studies in epidemiology (cohort, case-control and cross-sectional studies). This guideline is available on the link: http://www. strobe-statement.org/index.php?id=strobe-home

There are other guidelines following the same principles mentioned above such as: RATS (Regression Analysis of Time Series) used in the regression analysis studies; MOOSE (Meta-analysis of Observational Studies in Epidemiology); QUOROM (Quality of Reporting of Meta-analyzes) - the latter two, since 2005, have been incorporated, receiving the name of PRISMA (Preferred Reporting Items for Systematic Reviews and Meta-Analyses), used in studies of systematic review and meta-analysis -; the STARD (Standards for Reporting the studies of Diagnostic accuracy) that is used to validate diagnostic tests. Most of these protocols can be found in the portal (http://www.equator-network.org/). They are very useful for both postgraduate students who begin in their task of writing articles, as for already experienced researchers, but who do not know and do not yet benefit from this most recently built systematization incorporated to the arsenal of researchers in health

The quality of writing of scientific articles is one of the aspects that should be developed by teachers and it is important to improve this practice through courses and/or related activities, such as workshops on "how to write a scientific paper", following guidelines to adjust the papers to the specific rules of publication of each journal, etc.

\section{Strategies to get homogeneity}

The postgraduate programs need to invest in training their teachers, which must improve their knowledge in epidemiology for clinical studies, ethics in research and teaching. It is essential the participation of a statistician and a computer programmer in the research group from the project's planning phase and obtaining resources, until the publication of the results. This basically means to structure the office or place, which must be consistent and synergic with the postgraduate program. Involves availability of adequate space for the development of these activities, institutional coverage of salaries of other professionals such as statistician, programmers, network manager, accountant, research assistants, interviewers, typists, secretaries, etc., depending on the group size and scope. This can be funded both institutionally and by own research activity being developed by the group. There must be strict control in the development of research projects and submission of periodic reports on activities of the students, so that they all remain in day.

Articles should preferably be published in journals of international circulation, which are mostly in English. In cases of researchers who do not have full command of the language, the cost of qualified translation must be provided in the budget of the research project. In this case, the tutoring system previously mentioned also helps. Teachers who have full command of English can act as reviewers of papers in their semi-final stage, leaving the last review for professionals responsible for copy-editing, a procedure often used in practice today. However, the costs of such procedures should also be provided for and included in the budget initially submitted to potential funding agencies. While some agencies are still reluctant in the acceptance of such budgetary items, this procedure is increasingly being understood and accepted as legitimate, also including the publication fee charged by a large portion of the journals that exist only in online format and offer its content in free open access.

A valid strategy to publish articles in high quality journals 
is initially submitting it to journals with impact factor above that it was believed the height of the article, being the return or refuse a way to improve their quality through the use of feedback from reviewers. In addition to this advantage, if the manuscript is derived from a survey that was done in a serious and responsible manner, with adequate number of subjects and following all the methodological principles recommended for that kind of study, teacher and student may even have to see to surprise the paper being accepted by journal that was initially considered "above" the standard of the article. Due to the increasing number of publications each year and in order to facilitate the publication of articles, which is not an easy task, it has been developed programs that assist the author to identify more compatible journals with the profile of his/her article. The author places the title and abstract in the application that will perform search comparing the article with the millions of existing documents in Medline. As a result, the application will display the list of periodicals, ordered by confidence score, which correlates to the chances of have success in publication ${ }^{5}$. Two examples of these programs are the JANE (Journal/Author Name Estimator; http://www.biosemantics.org/jane/) and eTBLAST (http://etest. vbi.vt.edu/etblast3/).

Evaluation system of postgraduate programs in Brazil

It was with the university reform in 1968 that the postgraduate system in Brazil was developed, beginning in the 70's, at the time with the mission to train teachers and researchers, following the model of American universities. Since then, one of the goals of the Brazilian Federal Government was to promote the expansion of the postgraduate system, getting Capes responsible for both the financing of postgraduate courses, as per its evaluation ${ }^{6}$. Two of the postgraduate system characteristics in Brazil are the nucleation and solidarity, based in the capacity and/or interest of more structured programs to help beginner programs, cooperating with their activities ${ }^{6}$. The more structured programs are able to receive people from all over the country and to carry out the postgraduate program more with regional focus and, sometimes, only with a master degree ${ }^{6}$.

There are two postgraduate systems: the stricto sensu and lato sensu. The first has as its key feature the training of teachers and/or researchers and covers academic master courses, professional master's and doctorate. The second do not belong to Capes system and, so, has not the same formal quality evaluation system as the first, despite having significantly greater number of courses than stricto sensu ${ }^{6}$.

The professional master is a kind of postgraduate program, which aims to train professionals through the study of techniques, processes or topics, to contribute to the national productive sector. It can be an alternative in the quality of medical training before the doctorate. It has differentiated evaluation criteria and is evaluated by specific committees ${ }^{7}$.

Since 1998 the evaluation of the National Postgraduate System (SNPG) is guided by the Capes Assessment Board. Evaluators are indicated according to their performance in their respective areas and conduct independent, objective and impartial evaluation. The participation of the academic and scientific community in this evaluation system is essential in order to maintain the quality of master's and doctoral programs in the country. This system identifies regional differences and demands for scholarships and funding resources for research, enabling the guidance for opening and/or expansion of new programs in strategic sites ${ }^{8}$. The SNPG encourages the formation of postgraduate teachers at all levels, training of qualified personnel for non-academic world and strengthening scientific, technological and innovation bases ${ }^{8}$.
There are two assessments for postgraduate systems: one focused on proposals for new courses and another for the periodic evaluation of the ones already existed ${ }^{8}$. However, both processes are conducted with bases on the same grounds: the recognition and grounded reliability in quality ensured by peer review; methodology debated and updated by the academic and scientific community in each evaluation period and transparency in the disclosure of the decisions, actions and results, published in area pages in Capes portal ${ }^{8}$.

Thus, the desired homogeneity of the faculty of a postgraduate program as well as of the entire program, fundamentally depends on how the group leaders understand the process and what they really want for the program. The requirements for obtaining scores are defined by the respective areas of evaluation. Then, it is necessary to recognize whether the program has the resources (human, infrastructure, equipment, etc.) needed to proceed as recommended and obtain an evaluation consistent with that, and if the group wants it or not. Regardless of this discussion, which also has a bit philosophical nature, the fact is that good evaluation in the system means, directly or indirectly, a number of advantages in terms of getting grants, greater opportunities to obtain financial resources for research, the existence of technical conditions for the implementation of large studies, and more likely to have papers accepted in the highest impact journals, among others.

\section{Social impact of the postgraduation programs}

Capes values the social inclusion in the context of the activities of postgraduate programs, providing in their evaluation criteria, recognition activities with technological, cultural, educational and social impact ${ }^{9}$. In August 2007 the topic social inclusion was included in the evaluation form of stricto sensu postgraduate courses, which has $10 \%$ in weight in the evaluation of academic master's and doctorate. Since the professional master, which is characterized by having greater social impact, the weight may vary from $10 \%$ to $20 \%$ of the total evaluation, depending on the area ${ }^{9}$.

To postgraduate teachers/researchers that will work at other higher education institutions or research centers in other regions - often disadvantaged and with lower opportunity to work in consolidated research groups -, is one of the activities valued by Capes in this regard. Another important activity is the involvement of the program's fields of research on issues of national or regional importance, whose demand for innovations or scientific discoveries can bring great impact on society. It is recommended that teachers/researchers are in line with the themes chosen as priorities by ANPPS (National Agenda of Priorities for Health Research), which is good way to meet regional and national health needs, boosting selectively the knowledge production, material goods and in strategic services areas ${ }^{10}$.

\section{CONCLUSION}

Is there an ideal model of postgraduate program? We assume that there is no mathematical formula or ideal model of postgraduate program, but that each institution should suit and seek to improve its faculty and students in search of the best quality in its program, aimed at a particular target concept, respecting their possibilities, characteristics and requirements already predetermined by the evaluation of the existing postgraduate system in the country. For us this is the first and fundamental step to be followed, among all other mentioned above, which may culminate in having specific purpose on the assessment of excellence so considered by Capes. 


\section{RESUMO}

O docente tem importância fundamental no programa de pós-graduação, pois é quem planeja e executa grande parte das tarefas, sendo também o responsável por difundir conhecimentos aos alunos. O professor deve utilizar recursos didáticos que o qualifiquem continuamente, criando condições favoráveis para que o aluno se desenvolva e aprenda da melhor maneira e com mais facilidade. A homogeneidade no grupo de pós-graduação consiste da presença de subgrupos de pesquisa correspondentes às Áreas de Concentração, onde cada subgrupo trabalhe com algumas linhas de pesquisas diversificadas. É desejável que o corpo docente tenha significativa produção científica, de qualidade e distribuída homogeneamente entre os docentes. Estes devem sistematicamente buscar recursos em agências de fomento para pesquisa, tanto para o custeio dos estudos, quanto para a valorização dos pesquisadores envolvidos em todas as atividades. Os programas de pós-graduação precisam investir na formação de seus docentes, os quais devem aprimorar seus conhecimentos em epidemiologia de estudos clínicos, ética em pesquisa e em didática. Duas das características do sistema de pós-graduação no Brasil são a nucleação e a solidariedade, embasadas na capacidade e/ou interesse dos mais estruturados se solidarizarem com os programas iniciantes, cooperando com as suas atividades. A Capes valoriza a inserção social no contexto das atividades dos programas de pós-graduação, prevendo nos critérios de avaliação o reconhecimento de atividades com impacto tecnológico, cultural, educacional e social. Existe um modelo ideal de pós-graduação? Partimos do pressuposto de que não há uma fórmula matemática ou modelo ideal de pós-graduação e sim que cada instituição deve se adequar e buscar aperfeiçoar seu corpo docente e discente.

Descritores - Ensino; Instituições Acadêmicas; Corpo Docente; Conhecimento.

\section{REFERENCES}

1. Bolfer MM. Reflexões sobre prática docente: estudo de caso sobre formação continuada de professores universitários. Tese de Doutorado. Piracicaba: UNIMEP, 2008. p. 238. Disponível em http://www. unimep.br/phpg/bibdig/pdfs/2006/LWFMJKHNXBBS.pdf

2. Zhu Y, Zhang CJ, Hu CL. China's postgraduate education practices and its academic impact on publishing: is it proportional? J Zhejiang Univ Sci B. 2014; 15(12):1088-92.

3. Altman DG, Schulz KF, Moher D, Egger M, Davidoff F, Elbourne D, Gøtzsche PC, Lang T; CONSORT GROUP (Consolidated Standards of Reporting Trials). The Revised CONSORT Statement for Reporting Randomized Trials: Explanation and Elaboration. Ann Intern Med. 2001; 134(8):663-94.

4. Moher D, Hopewell S, Schulz KF, Montori V, Gøtzsche PC, Devereaux PJ, Elbourne D, Egger M, Altman DG; Consolidated Standards of Reporting Trials Group. CONSORT 2010 Explanation and Elaboration: Updated guidelines for reporting parallel group randomised trials. $J$ Clin Epidemiol. 2010; 63(8):e1-37.

5. Schuemie MJ, Kors JA. Jane: suggesting journals, finding experts. Bioinformatics. 2008; 24(5):727-8. Available from: http://bioinformatics.oxfordjournals.org/content/24/5/727. abstract
6. Brasil. Ministério da Educação. Plano Nacional de Pós-Graduação - PNPG 2011-2020. Brasília: Capes, 2010. Available from https:// www.capes.gov.br/images/stories/download/PNPG_Miolo_V2.pdf

7. Brasil. Ministério da Educação. Mestrado Profissional: o que é ? Brasília: Capes, 2014. Available from: http://www.capes.gov.br/ avaliacao/sobre-a-avaliacao/mestrado-profissional-o-que-e

8. Brasil. Ministério da Educação, CAPES - Coordenação de Aperfeiçoamento de Pessoal de Nível Superior. Sobre a Avaliação. Brasília: Capes, 2014. Available from: http://www.capes.gov.br/avaliacao/ sobre-a-avaliacao

9. Ribeiro RJ. Inserção social [Internet]. [cited 2015 Mar 16]. Available from: https://www.capes.gov.br/images/stories/download/artigos/ Artigo_23_08_07.pdf

10. Ministério da Saúde. Decit - Departamento de Ciência e Tecnologia. Pesquisa em saúde no Brasil. Rev Saude Publica. 2008; 42(4):773-5.

Received on: 19/02/2015

Accepted for publication: 12/09/2015

Conflict of interest: none

Source of funding: none

Address for correspondence:

José G Cecatti

cecatti@unicamp.br 